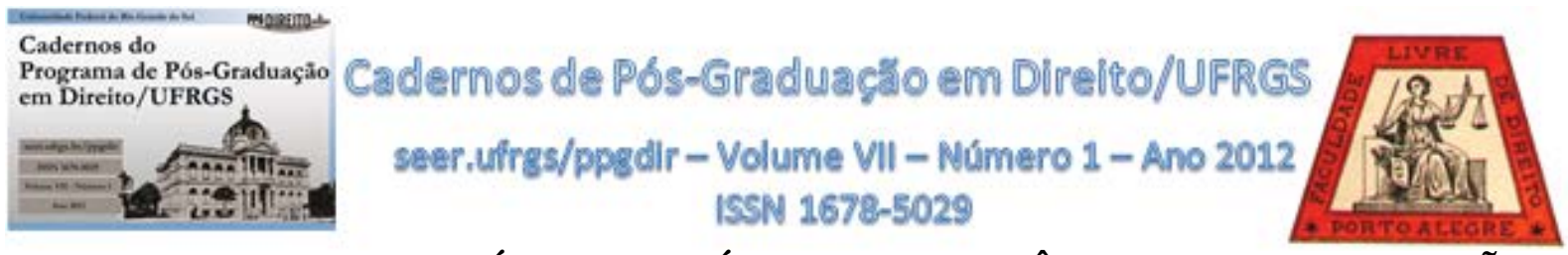

\title{
FUNDAMENTOS FILOSÓFICO-POLÍTICOS DO FENÔMENO DA CORRUPÇÃO: CONSIDERAÇÕES PRELIMINARES
}

\section{FUNDAMENTALS OF PHILOSOPHICAL-POLITICAL CORRUPTION PHENOMENON: PRELIMINARY CONSIDERATIONS}

Professor Rogério Gesta Leal

Sumário: Introdução. 1 As múltiplas faces da Corrupção. 2 No que a filosofia pode auxiliar à compreensão da Corrupção. 3 Conclusão. Referências

Resumo: O presente ensaio pretende enfrentar o tema dos fundamentos filosóficos e políticos da corrupção como fenômeno institucional, cultural e social, a partir de reflexões da ciência política e da filosofia, e de que maneira isto se conecta ao jurídico.

Palavras-chave: Corrupção; Institucional; Direito Público; Ciência Política; Fenômeno.

Abstract: This paper intends to address the philosophical and political fundamentals of corruption as a institutional, cultural and social phenomenon, from political science and philosophy reflections, and how it connects to the legal themes.

Keywords: Corruption; Institutional; Public Law; Politic Science, Phenomenon.

\section{INTRODUÇÃO}

Pretendo neste texto trazer alguns elementos de reflexão sobre este problema social, político e institucional que é a corrupção, e de que forma ele contamina ou por vezes constitui as relações sociais. Tais elementos encontram-se, como proposta do texto, em múltiplas fontes filosóficas e da ciência política (sem falar da sociologia, antropologia, etc.), razão pela qual vou lançar mão para esta tarefa de algumas matrizes destes saberes.

Em termos estruturais, minha abordagem dar-se-á sobre os argumentos filosóficos mais clássicos que tentam compreender o fenômeno da corrupção a partir dos seus contornos de fundamentação.

\section{AS MÚLTIPLAS FACES DA CORRUPÇÃO}


A corrupção tem evidenciado ao longo do tempo faces multisetoriais e capacidade de expansão infinita na rede de relações sociais e institucionais, públicas e privadas, do cotidiano, nos últimos tempos ganhando maior notoriedade em face da difusão e redifusão midiática tradicional (jornais, televisão, rádio) e alternativa (blogs, twiters, facebooks, redes sociais, etc.), não se extraindo daí, em regra, análises, diagnósticos e prognósticos mais aprofundados de suas causas e conseqüências.

A despeito dos aspectos positivos desta progressiva amplitude da transparência material e formal (há mais leis, tratados, convenções, pactos, sentenças judiciais e procedimentos administrativos que se ocupam do tema) que surge em torno da corrupção, gerando até reflexos sobre a opinião pública de massa, que resgata a capacidade de indignação quanto a isto, o que se afigura importante, isto tampouco dá conta da complexidade deste fenômeno.

Por outro lado, o debate sobre corrupção tem se centrado nos seus aspectos econômicos e jurídicos no Ocidente, todavia, o problema é quando estes âmbitos de enquadramento restringem outras abordagens que dizem com causas e conseqüências para além deles, deixando de se reconhecer que, em verdade, que a corruption destroys the fundamental values of human dignity and political equality, making it impossible to guarantee the rights to life, personal dignity and equality, and many other rights. ${ }^{1}$

É fácil entender que tais restrições de compreensão do fenômeno sob comento também são decorrência do foco e da intensidade das violações econômicas e jurídicas que a ele provoca, pois ocorre mesmo o que Klitgaard chama de capture of the state by elites and private interests. $^{2}$

É possível diferenciar entre corrupção provocada para ganhos públicos e ganhos privados? Ou mesmo entre corrupção provocada pelo setor público e pelo setor privado? If ordinary citizens lie when they give testimony in court, this is corruption; it is corruption of the criminal justice system. However, it does not involve abuse of a public office by a public

\footnotetext{
${ }^{1}$ KLITGAARD, Robert. Controlling Corruption. Berkeley: University of California Press, 1991, p.33.

${ }^{2}$ Idem, p. 48. Lembra, neste particular, MOODY-STUART, George. Grand Corruption: How Business Bribes Damage Developing Countries. Oxford: World View Publishing, 1997, p.45, que: "Corruption demands a multidisciplinary approach, and many fields of study, from political science to economics, have addressed the issue. Each has a different perception of the problem and therefore generates different policies: operational definitions tend therefore to start broad and become more specific as they try to render corruption measurable. A well-known classification distinguishes grand from petty corruption. Grand corruption refers to the corruption of heads of state, ministers, and top officials and usually involves large amounts of assets. Petty corruption also called "low" and "street" corruption indicates the kinds of corruption that people experience in their encounters with public officials and when they use public services (hospitals, schools, local licensing authorities, police, tax offices, etc.). It generally involves modest sums of money." Tal perspectiva reduz em muito o conceito de corrupção a sua dimensão econômica, com o que não concordo.
} 
official. And when police fabricate evidence out of a misplaced sense of justice, this is corruption of a public office, but not for private gain. ${ }^{3}$

Ocorre que há outras situações corruptivas que não se amoldam perfeitamente às dimensões monetárias e normativas de suas existências, como por exemplo na relação entre suborno e nepotismo, sob o instigante argumento de Miller, The person who accepts a bribe is understood as being required to provide a benefit to the briber, otherwise it is not a bribe; but the person who is the beneficiary of an act of nepotism is not necessarily understood as being required to return the favor. ${ }^{4}$

A perspectiva norte-americana do conceito de corrupção destaca o impacto que comportamentos corruptivos - sejam quais forem, e cada vez mais estende a caracterização destes - provocam nas instituições e nas relações sociais, eis que dá como exemplo: (a) a situação dos médicos que cerram fileiras em não denunciar ou sequer testemunharem contra colegas seus que foram negligentes no tratamento da vida humana; (b) quando a polícia fabrica provas para serem usadas em processos; (c) quando determinados patrocinadores de atletas em competições importantes os estimulam e mesmo obrigam a consumir produtos fármacos proibidos para obterem melhores resultados; (d) o próprio tema do nepotismo, que não precisa ter contraprestação econômica - suborno - para se caracterizar; isto porque, em todos estes exemplos, o que se distingue é a quebra de confiança no sistema na medida em que procedimentos institucionais são solapados, a despeito de em tais situações não haver a configuração explícita ou ao menos tradicional do suborno propriamente dito. ${ }^{5}$

Veja-se que esta questão do suborno remete à associação do tema da corrupção a causas predominantemente ou exclusivamente econômicas, donde surge o questionamento: "To some extent this kind of view reflects the dominance of economically focused material in the corpus of academic literature on corruption. It also reflects the preponderance of proposed economic solutions to the problem of corruption. After all, if corruption is

\footnotetext{
${ }^{3}$ MILLER, Seumas. The Moral Foundations of Social Institutions: A Philosophical Study. New York: Cambridge University Press, 2010, p.61.

${ }^{4}$ MILLER, Seumas, ROBERTS, Peter \& SPENCE, Edward. Corruption and Anti-Corruption: An Applied Philosophical Approach. New Jersey: Prentice Hall, 2008, p.44.

${ }^{5}$ Idem. Algumas situações corruptivas podem, em alguns países, não configurarem crimes ou ilícitos a serem punidos, mas de igual sorte violam Direitos Fundamentais consagradas por conquistas sociais, dizendo o autor que: "Corrupt practices that may not necessarily be illegal and thus cannot be counterattacked through law enforcement can be combated through the human rights machinery. For instance, in many judicial systems nepotism or political favouritism are not considered corruption in strict legal terms, i.e. it is not prohibited by the law. However, such practice may result in a violation of the rights of political participation and right to equal access to public service. In these cases human rights constitute a way out from strict legal rules. If a corrupt practice does not satisfy legal requirements it may still result in a human rights violation and if it is regarded, understood and explained in terms of a human rights violation such practice may be overruled." (p.55).
} 
essentially an economic phenomenon, is it not plausible that the remedies for corruption will be economic ones?" 6

Neste mesmo exemplo, pode-se defender a tese de que a corrupção não pode ser restringida a ilicitudes ou a problemas meramente jurídicos porque, na iniciativa privada das relações de produção de bens e serviços tem se criado formas não oficiais de premiação ou bonificação de comportamentos e condutas profissionais, basta ver a já institucionalizada gorjeta para garções em bares e restaurantes, não se caracterizando isto como forma corruptiva de obter favores especiais por parte dos atendentes destes locais, mas mesmo como reconhecimento suplementar, por parte do usuário, do serviço levado a cabo. Não há aqui atribuição de sentido negativo ao ato de dar e receber a gorjeta, isto porque ela não tem em si elementos contaminadores da boaf-fé das pessoas envolvidas, ou sequer é capaz de gerar fenômenos de desvios de finalidade/poder por parte de quem presta o serviço. ${ }^{7}$

Aliás, é de se dizer que a gorjeta é a única parcela variável no âmbito das relações laborais e sua contraprestação que tem previsão legal no Brasil, uma vez que o art. 457, da Consolidação das Leis do Trabalho - CLT, determina que, na remuneração do empregado, para todos os efeitos legais, compreende-se, além do salário devido e pago diretamente pelo empregador, como contraprestação do serviço, as gorjetas que receber. $\mathrm{O} \S 3^{\circ}$, do art. 457, considera gorjeta não só a importância paga espontaneamente pelo cliente ao empregado, como também aquela cobrada pela empresa prestadora do serviço como adicional nas contas destinadas à distribuição aos empregados.

A outros exemplos no campo da não restrição motivacional-econômica de atos corruptivos - ao menos não diretamente -, tais como situações de plágio acadêmico, no qual o plagiador não precisa estar motivado necessariamente por um ganho de ordem econômica, mas a um benefício de desempenho curricular ou formativo (por mais ficcional que o seja), como a conclusão de um curso ou especialização, para então se colocar melhor no mercado; a situação do agente público que fabrica ou planta provas incriminatórias em ilícitos penais de alta reprovação social (pois há alguns que não o são mais, como o jogo do bixo, por exemplo), como o estupro ou pedofilia, não desejando com isto qualquer vantagem econômica ou benefício pessoal, mas animado por senso de justiça pessoal/social de que um estrupador e pedófilo não seja punido. Como diz John Crank, “Many of those who occupy positions of

\footnotetext{
${ }^{6}$ MILLER, Seumas \& BLACKLER, John. Ethical Issues in Policing. Aldershot: Ashgate, 2005, p.110.

${ }^{7}$ Há empresas que inclusive criam prêmios e bonificações por resultados de atividades profissionais, como forme de fomento às iniciativas do mercado. Atente-se para o fato de que Nos EUA, até o final da década de 1070, "it was not unlawful for US companies to offer bribes to secure foreign contracts; indeed, elsewhere such bribery was not unlawful until much later". Idem.
} 
authority are motivated by a desire to exercise power for its own sake, rather than by a desire for financial reward". 8

Por outro lado, não se pode dissociar o tema da corrupção institucional da pessoal, pois:

\begin{abstract}
"It is plausible that corruption in general, including institutional corruption, typically involves the despoiling of the moral character of persons and in particular, in the case of institutional corruption, the despoiling of the moral character of institutional role occupants qua institutional role occupants. To this extent institutional corruption involves personal corruption."
\end{abstract}

Há uma dimensão simbólica do que significa a corrupção em termos de valores democráticos que independe dos seus efeitos práticos e quantitativo-financeiros, ou mesmo os que dizem com sua consumação de benefício ou não - modalidade da tentativa, pois estão em jogo as bases normativo-principiológicas fundantes das relações sociais e da confiança nas instituições representativas - públicas e privadas. ${ }^{10}$

Daí a conclusão de que não importa tanto o dimensionamento econômico do prejuízo causado pelos atos corruptivos, mas o próprio ato implica violação de direito per si. Em face disto, Seumas Miller dá o exemplo envolvendo o fornecimento, por parte de proprietário de lancheria, de um hambúrguer a um policial, como cortesia ou reconhecimento pelo seu trabalho na segurança pública em geral, não configurando ato corruptivo típico; outra coisa, porém, é haver atos continuados de fornecimento de hambúrgueres ao mesmo policial ou a vários policiais com o fim de ampliar ou garantir proteção especial de segurança pública. ${ }^{11}$

Mas será que se pode falar em causas nobres que justifiquem a corrupção? Miller sustenta que não, e com ele concordo, dando o exemplo do caso em que um servidor público

\footnotetext{
${ }^{8}$ CRANK, John \& CALDERO, Michael. Police Ethics: The Corruption of Noble Cause. Cincinnati: Anderson Publishing, 2004, p. 24. Refere o autor, mais tarde, que: "There are a variety of different kinds of attractions that motivate corruption. These include status, power, addiction to drugs or gambling, and sexual gratification, as well as economic gain.” De qualquer sorte é pacífico o entendimento hoje de que há uma relação efetiva entre o fenômeno da corrupção e a violação de Direitos Fundamentais, sendo imperioso entender bem "how the cycle of corruption facilitates, perpetuates and institutionalises human rights violations”. (p.59).

9 ABED, George T. \& GUPTA, Sanjeev (eds.). Governance, Corruption, and Economic Performance. Washington DC: International Monetary Fund, 2003, p.38. Diz ainda o autor que: "the close relationship between institutional roles on the one hand, and institutional processes and purposes on the other, explains why institutional corruption typically involves both the despoiling of institutional role occupants and the undermining of institutional processes and purposes."

${ }^{10}$ Neste ponto, há interessante questionamento de Baker: "But if an employee of a private company is bribed by a contractor of the company, is this also a question of corruption? Most would still regard it as a corrupt act, but there exists a minority which holds that the term "corruption" is limited to acts that take place within the public sector". BAKER, Raymond. Capitalism's Achilles Heel: Dirty Money and How to Renew the Free-Market System. Indianapolis: Wiley, 2005, p.33. Ver também o texto de UNITED NATIONS COMMISSION ON HUMAN RIGHTS, Interim Report of the Special Representative of the Secretary-General on the Issue of Human Rights and Transnational Corporations and Other Business Enterprises, U.N. Doc. E/CN.4/2006/97, 22 February 2006, para. 25/27.

${ }^{11}$ MILLER, Seumas. The Moral Foundations of Social Institutions: A Philosophical Study. Op.cit., p.70
} 
da imigração permite o ingresso irregular de estrangeiro amigo seu no país para que ele possa receber tratamento médico vital a sua saúde, operando verdadeira violação (ou corrupção no sentido de subversão) do sistema e procedimento de imigração, sem qualquer benefício pessoal. Todavia, "But from the fact that the person was not corrupted it does not follow that the act did not corrupt. Moreover, it does not even follow that some person or other was not corrupted. Clearly, in our example, the immigration official was corrupted.”12

Por este raciocínio se esmorece o conceito de corrupção dado, por exemplo, pela instituição Transparência Internacional, no sentido de que corruption is the abuse of entrusted power for private gain, pois, em tal perspectiva, poderia se admitir o abuso da confiança depositada para ganhos públicos?!

Há, pois, muitas causas e nexos causais que envolvem atos corruptivos (comissivos e omissivos), todos com níveis de complexidade constitutivos muito altos, reclamando a madura e aprofundada reflexão, no que a filosofia pode em muito auxiliar, o que passo a fazer, todavia, concentrando a interlocução com o que se pode chamar de filosofia política mais clássica, sem abordar, agora e com profundidade, autores contemporâneos.

\section{NO QUE A FILOSOFIA PODE AUXILIAR À COMPREENSÃO DA CORRUPÇÃO}

No plano gramatical do termo, a corrupção é substantivo feminino derivado do latim corruptĭo, com o sentido de deterioração, ato, processo ou efeito de corromper. De acordo com o Dicionário Houaiss da Língua Portuguesa e Dicionário da Língua Portuguesa Contemporânea, da Academia das Ciências de Lisboa —, este substantivo pode significar: a) deterioração, decomposição física, orgânica de algo ou putrefacção; b) modificação, adulteração das características originais de algo; (c) no sentido mais figurado, a expressão refere também a degradação moral de indivíduos e instituições, o que evidencia a ampla gama de possibilidades conceituais em jogo.

Claro que é difícil sustentar a existência de códigos morais de comportamentos individual e social rídigos e inflexíveis, até pelo fato do reconhecimento à diferença e à telerância como Direito Fundamental de cada qual no convívio com seus semelhantes, mas também isto não significa dizer ser possível aceitar-se qualquer coisa em termos de hábitos ou condutas sob o mesmo fundamento, isto porque há mínimos existenciais conquistados pela

\footnotetext{
${ }^{12}$ MILLER, Seumas \& BLACKLER, John. Ethical Issues in Policing. Op.cit., p.115.
} 
Civilização Contenporânea que colocam a natureza humana como protegida de violações notadamente em face da ampliação de prerrogativas, princípios e regras (internacionais, constitucionais e infraconstitucionais) asseguradoras de sua dignidade.

Assim, o problema que se coloca é saber em que medida é defensável a existência de uma moralidade pública e outra privada capazes de auxiliar na orientação (porque não são suficientes) das possibilidades de controle e tratamento curativo e preventivo de atos corruptivos - aqui sempre entendidos como aqueles que dizem respeito aos corruptores e corrompidos, inexistindo discrimem entre eles ao menos neste âmbito.

A filosofia de Aristóteles já tratava destas questões, referindo-se à importância da Virtude (Arete) na vida humana, compreendida também como aquela que é moralmente aprovada, não porque atende determinados fins, mas porque tem elementos universais que lhe permite o reconhecimento universal. Nas palavras de Tugendhat: "Embora no grego não haja nada mais natural do que no caso da virtude falar de um objeto de uso ou de um ginasta, isso não significa que, quando se fala das virtudes dos seres humanos enquanto seres humanos, isso seja compreendido funcionalmente; fala-se das propriedades do caráter dignas de aprovação (louváveis).”13

Nesta linha de raciocínio, a Modernidade trouxe os conceitos de moralidade e virtude aristotélicos para seus dias, no sentido da virtude ser compreendida como disposição firme da vontade de agir segundo a regra/norma pela qual é definido o BEM.

O cuidado que se tem de ter é no sentido de que tal definição não se funde sobre o que é bom pragmaticamente para mim, mas bom em si, ou seja, que diga respeito a determinados valores cujo cultivo se afigura necessário para que alguém, independente dos objetivos que tenha individualmente, possa estar bem consigo e com seu semelhante, partindo-se da premissa de que não é possível o estado de bem estar totalmente isolado do universo em que ocorre.

Daí a preocupação de Platão com os governos dos homens de honra (regime timocrático), os quais não poderiam deixar de contar com as orientações dos filósofos, sob pena de deixarem de se orientar pelo interesse geral, com a glória e a defesa da cidade, passando então a reclamar honras e benefícios pessoais, introduzindo na pólis o orgulho e a violência, cindindo sua unidade harmoniosa e dividindo-a em castas de dirigentes nobres e dirigidos ignóbeis. ${ }^{14}$

\footnotetext{
${ }^{13}$ TUGENDHAT, Ernst. Lições sobre Ética. Petrópolis: Vozes, 1999, p.245.

${ }^{14}$ PLATÃO. A República. Belém: Edufpa, 2000. Ver também o texto PLATÃO. As Leis. Belém: Edufpa, 1980.
} 
Tal norma que define o BEM, além de moral e ética, para homens de virtudes, precisa também ser constitutiva das possibilidades civilizatórias das relações humanas em Sociedade, ou seja, em contextos culturais, políticos, de trabalho, religiosos, sexuais, educacionais, etc., específicos, razão pela qual devem operar de igual sorte como imperativos de ação, comportamentos e condutas individuais em prol da Sociedade constituída - base do normativismo contratualista do século XVII. Isto está muito presente em Kant, como ensina Tugendaht:

\begin{abstract}
“A moral de Kant é entretanto uma moral de regras, e não porque ela se funda num princípio, mas porque o princípio é pensado como um princípio que se refere aos conteúdos do contratualismo, ou, para expressá-lo mais claramente quanto ao conteúdo, porque Kant pensou o princípio como um princípio que é concretizado de uma maneira que permite enumerar as máximas ordenadas, isto é, as regras de ação."15
\end{abstract}

O problema de esta norma (regra/princípio) ser única ou não - como quer Kant, com seu imperativo categórico -, já não é pacífico na filosofia e mesmo na antropologia, sociologia e ciência política, até pelo fato do reconhecimento de que, no plano das chamadas éticas das virtudes, sempre existe uma número maior de virtudes, tornando a equação do imperativo categórico menos absoluta. ${ }^{16}$

Estou querendo dizer que o excesso de subjetividades e experiências de comunidades distintas desde a Modernidade, reconhecidas como legítimas sob a perspectiva do convívio social, induz a uma dimensão política da Moral moderna, a qual impõe a moral de regras como central no âmbito das relações individuais e sociais contemporâneas, aqui formatada em termos de leis de Estado, laicas e mundanas, que estão a demarcar as possibilidades espaciais e temporais de efetivação do BEM, ao menos em termos de mínimos existenciais, ou seja, ultrapassando o conceito de virtude individual universal, que se potencializa com o desenvolvimento de certas virtudes nos cidadãos.

Tais dimensões normativas - jurídicas - da idéia de BEM (ainda na perspectiva filosófica aristotélica, na Ética a Nicômaco), poderiam dizer com as possibilidades de sentido

\footnotetext{
${ }^{15}$ TUGENDHAT, Ernst. Lições sobre Ética. Op.cit., p.248. O autor ainda vai lembrar que a moral kantiana, ao contrário da opinião corrente, na é uma moral de regras por ter ela um princípio de julgamento unitário.

${ }^{16}$ É interessante notar que Aristóteles, na Ética a Nicômaco, I-6, já advertia para o fato de que: “a palavra bem tem tantos sentidos quantos ser..., está claro que o bem não podo ser algo único e universalmente presente, pois se assim fosse não poderia ser predicado em todas as categorias, mas somente numa. Ainda mais: como das coisas que correspondem a uma Idéia a ciência é uma só, haveria uma única ciência de todos os bens. Mas o fato é que as ciências são muitas, mesmo das coisas que se incluem numa só categoria.” ARISTÓTELES. Ética a Nicômaco. In Aristóteles (II), coleção Os Pensadores. São Paulo: Abril Cultural, 1984, p.53.
} 
objetivo de FELICIDADE ${ }^{17}$, e, portanto, criam parâmetros métricos gerais para que o ser humano virtuoso (localizado historicamente) possa, através da reflexão (lógos), dirigir/escolher seu bem estar (prohairesis), e o faz não somente para obter um fim específico que atenda exclusivo interesse próprio, mas tal comportamento e seu fim serão perseguidos em razão de uma determinada atitude perante os outros também.

\begin{abstract}
"Falar agora em equilíbrio não é mais empregar uma fórmula vazia, porque os extremos têm um sentido próprio: representam as possibilidades polares deficitárias na ponte que cada um lança aos outros nas diferentes dimensões do convívio. Todas estas virtudes sociais são excelências do comportamento emque nos abrimos ou nos fechamos diante dos outros. O comportamento para com os outros é como um ato de equilibrismo entre a perda da relação e a perda de si mesmo, entre autonomia e dependência (Bezogenheit). Os extremos são, de sua parte, modos de ser identificáveis, e esta é a razão por que falar de equilíbrios não é uma fórmula vazia." 18
\end{abstract}

$\mathrm{Na}$ perspectiva jurídica, creio ser possível responder à adequada reflexão de Tugendhat, referindo-se a estas considerações aristotélicas, no sentido de que: “Todas estas características deixam, porém, em aberto como o padrão da medida da reflexão deve ser compreendido. O que consideramos quando tomamos, no continuum de nossas possibilidades de afeto, um lugar determinado na areté? O ponto de vista é, por sua vez, o bem estar ou algo previamente dado (ein vorgegebener)?”19. À contemporaneidade, por certo que se deve comsideraw às escolhas públicas um lugar determinado não por juízos subjetivos exclusivos por mais elevados que sejam -, mas também os marcos normativos identificatórios do bem que já foram estabelecidom por opções anteriores (via processos legislativos próprios que criam leis vinculantes a todos). ${ }^{20}$

\footnotetext{
${ }^{17}$ Idem, Livro II, capítulos 5 e 6, quando trata das virtudes (pp.71/73). Falo de UMA das possibilidades porque Aristóteles, como lembra Tugendhat, deixou de elaborar um conceito de virtude moral enquanto tal, e sequer se ocupou de estruturar um conceito geral de moral, portanto, "da questão do sobre o bem, como o realmente querido, para a do bem, como o socialmente aprovado.......Daí decorre que toda a doutrina da virtude de Aristóteles oscila entre as duas possibilidades: trata-se de virtudes de felicidade (Glückstugenden) ou de virtudes morais? Aristóteles pretende naturalmente mostrar, exatamente como Platão pretendeu, que somente quem possui virtudes morais é feliz.” TUGENDHAT, Ernst. Lições sobre Ética. Op.cit.,268.

${ }^{18}$ Idem, p.276.

${ }^{19}$ Idem, p.265. Lembra o autor aqui da areté psíquica de Aristóteles, "entendida como uma hexis, como um "comportar-se" (Sichverhalten) para com os afetos, e, além disso, que deve ser sempre entendida como uma firme disposição da vontade de escolher corretamente entre os sentimentos (prohairesis). A prohairesis, a escolha, é o resultado de uma reflexão (III,4-5).”

${ }^{20}$ Digo isto desde aqui exatamente para lembrar a advertência que faz Tugendhat no sentido de que "é impossível às virtudes, no sentido de Aristóteles, indicar regras de ação, não apenas devido à complexidade excessiva, mas por não se referirem absolutamente a ações que possam ser definidas pela indicação de seus fins. Aristóteles reflete aqui, portanto, sobre um fato fenomênico que desde o início não pode ser absolutamente definido por regras. Agora também se pode compreender melhor até que ponto o ser-assim que se expressa na virtude é o que é em primeira linha aprovado, e as ações em que se manifesta, apenas secundariamente, e na medida em que este ser-assim se mostra nelas.” (Idem, p.275).
} 
O problema é que a política, sob o ponto de vista das disputas eleitorais e de governança, é pautada, em regra, não pela razão teórica do homem virtuoso que está mais compromissada com a moral e a ética do dever ser, mas à razão prática e pragmática dos fins imediatos de projetos institucionais, pessoais e corporativos, o que contamina a virtude cívica dos cidadãos e vicia a legitimidade de determinados modelos e experiências da democracia representativa, haja vista a ausência de consensos em torno de valores e princípios que a sustentem.

Por isto é que Cícero, seguindo Panetius, alertava para o fato de se atentar para determinados critérios na eleição de escolhas e decisões práticas envolvendo a política e o interesse público, a saber:

\begin{abstract}
"Se o que se apresenta é honesto ou desonesto; sobre isto o pensamento muitas vezes se confunde. Em segundo lugar, procura-se saber se a decisão aumenta as coisas agradáveis e as comodidades da vida, as riquezas, os recursos, o poder, o crédito, enfim, se há conveniências para si e para os outros; esta segunda relação se atrela à utilidade. Por último, trata-se de saber se aquilo que parece útil no aspecto, não se opõe ao honesto, quando a honestidade nos detém de um lado e o interesse do outro, nessa dúvida o espírito se encontra nos dois sentidos." ${ }^{21}$
\end{abstract}

Cícero ainda traz orientações ao governante para que evite a corrupção, sustentando que: (a) quem desejar o governo deve ter em conta duas regras platônicas básicas, a saber, que é preciso ter em vista apenas o bem público, sem se preocupar com situações pessoais; que é imperioso que o governo estenda sua preocupação do mesmo modo a todo o Estado, não negligenciando uma parte para atender a outra; (c) é preciso no governo afabilidade e moderação, mas, quando se trata do bem do Estado, é preciso severidade, sem a qual o governo se torna impossível. ${ }^{22}$ Assim, diante de atos corruptivos, a energia do controle e da responsabilidade deveria ser extrema.

Há um retrocesso desta avaliação na Idade Média, em especial com a mudança de paradigma imposta pelo cristianismo à compreensão do fenômeno político e suas desviantes. Como diz Filgueiras:

\footnotetext{
${ }^{21}$ CÍCERO, Marco Túlio. Dos Deveres. São Paulo: Martin Claret, 2001, p.34. É somente a razão humana que transforma em beleza, assiduidade e ordena os desejos e ações humanas, resguardando o homem da desonestidade e covardia; preservando-o da paixão tanto para seus sentimentos como para seu comportamento. "De tudo isto decorre a honestidade procurada, honestidade que nada perde de sua beleza, mesmo quando não seja notada e que é louvável por si própria, ainda quando por ninguém louvada.” (p.35). Não desconheço o compromisso do autor com a ordem estabelecida em termos de estamentos sociais em Roma, notadamente quando afirma que "A honestidade consiste em descobrir a verdade pela astúcia do espírito, ou em manter a sociedade humana dando a cada um o que é seu e observando fielmente as convenções;” (p.35), mas o que me interessa sublinhar aqui são os elementos morais e éticos de gestão da coisa pública que o autor constrói.

${ }^{22}$ Idem, p.48.
} 


\begin{abstract}
“A Idade Média também assistiu a uma mudança conceitual da temática da corrupção, uma vez que o pensamento político estaria marcado pelo dogma cristão e pela existência de uma ontologia cindida entre dois mundos. De um lado, há a mundanidade infinita, pertencente ao reino de Deus, capaz de assegurar, de acordo com Santo Agostinho, as devidas virtudes capazes de gerar a integridade de uma república. De outro lado, a par do mundo sagrado, existe a mundanidade finita, pertencente ao reino dos homens, na qual a corrupção, traduzida como o luxo e a cobiça, desempenha o papel de redenção à fé cristã, além de fazer parte da condição decaída em que se encontravam os homens." 23
\end{abstract}

Lembra Gibbon que na Idade Média se pode observar como o Cristianismo impactou o interesse do homem comum do povo pela política e gestão do interesse público, na medida em que exaltou o amor e respeito às autoridades divinas em detrimento dos negócios da República/Cidade, dando ensejo a comportamentos mais contemplativos e reflexivos do que interativos com as demandas empíricas dos atos de governo. ${ }^{24}$

Já no tempo de Maquiavel, no século XV, estas questões vão voltar à tona com mais vigor, em especial no sentido de que o discurso ético e político tiveram de procurar outros fundamentos que não os metafísicos e teológicos até então vigentes na cultura européia, sob o fundamento de que inexistem transcendências a serem invocadas nesta ceara, mas fatos a serem questionados, interpretados e erigidos como fundadores de racionalidades históricas concretas, sobre os quais se elevam os valores humanos, principalmente no campo político e governamental.

É preciso ter presente aqui que, enquanto que a França, a Inglaterra e a Espanha conseguiam, mal ou bem, controlar as tendências libertárias desse tempo, instalando a unificação administrativa e política através de um governo forte e centralizador, na Itália o guelfismo popolare quebrou o domínio do Sacro Império Romano, tornando independentes as cidades do setentrião e do centro, pela força do novo espírito demoliberal de sua burguesia, configurando-se impossível o reagrupamento pacífico daquelas unidades emancipadas em um grande e só Estado. Permaneceram desunidas, esfaceladas em pequenas cidades-Estados, dominadas por uma aristocracia ambiciosa ${ }^{25}$.

As qualidades do bom governante, assim, se fundariam na virtù e na fortuna, fatores eminentemente empíricos e contingenciais. A primeira característica é a da energia, decisão e

\footnotetext{
${ }^{23}$ FILGUEIRAS, Fernando. Corrupção, Democracia e Legitimidade. Belo Horizonte: UFMG, 2008, p.55. Lembra ainda o autor que: "Desse modo, não haveria uma preocupação, por parte da Igreja, com a temática da corrupção, uma vez que a condição dos homens se fazia decaída, cabendo apenas à contemplação, e não às virtudes, do conhecimento prático, o papel da salvação.” (p.56).

${ }^{24}$ GIBBON, Edward. Declínio e queda do Império Romano. São Paulo: Companhia das Letras, 1989.

${ }^{25}$ Conforme o texto de RIDOLFI, Ricardo. Vita di Niccolò Machiavelli. Roma: Domenico, 1974, pg.32 e ss. Ver também o texto de HALE, Jonh. Maquiavel e a Itália da Renascença. Rio de Janeiro: Zahar Editores, 1970.
} 
capacidade para fazer valer um objetivo estabelecido, sem, entretanto, atrelar-se ao sentido cristão e metafísico da virtude, que pressupõe compromisso ético e religioso em vista de um fim sobrenatural; a segunda, tem o significado de oportunidade, momento propício que tem o Príncipe para tomar suas decisões com eficácia e com a certeza do êxito. ${ }^{26}$

A partir de Maquiavel o Estado Nacional e Soberano que irá se formar nos umbrais da Idade Moderna, depois de ter abalado a tutela imperial, feudal e pontífice, em seguida poderá se emancipar da tutela do direito natural, da justiça, da moral corrente, tão somente válida para os indivíduos. E esta parece ser uma das mais festejadas contribuições do autor à teoria política moderna, i.e., estabelecer uma ruptura entre o exercício do governo e as pautas morais de comportamento e condutas, tão preconizadas e perquiridas pela Igreja medieval. “Se o Secretário florentino imprimiu uma marca tão profunda, tão indelével, na ciência e na arte do poder, foi por ter proclamado com tanta força tranqüila a separação radical entre a política e a moral corrente, entre a autonomia da política e sua prioridade: a política em primeiro lugar."27

Daí que só o Estado positivo e mundano teria condições de frear as paixões que, entregues a si mesmas, levariam a comunidade ao colapso, inclusive detratando os seus próprios. ${ }^{28}$ Essa positividade só poderia se dar pela normatização do cotidiano do cidadão, que iria regular e controlar condutas e comportamentos societais, exatamente para preservar as diferenças sociais gritantes entre o popolo grasso - os grandes burgueses italianos - e o

\footnotetext{
${ }^{26}$ Note-se que o estoicismo, movimento que surgiu por volta de 300, a.C., em Atenas, mas que influenciou a cultura romana até cerca de 200, d.C., fez contribuições importantes para o pensamento de Maquiavel, nomeadamente quando enfrentava questões como a moral, a importância do raciocínio para o conhecimento da natureza, dos princípios de organização social e do valor de se levar uma vida feliz. Ver neste sentido os trabalhos de MACHIAVELLI, Niccollò. Discursi sul a Prima Década di Tito Lívio. Nápoles: Daltricce, 1978; TERRIEL, Jean. Les theories du pacte social Droit naturel, souveranite et contract de Bodin a Rousseau Paris: PUF, 2001. Há também os textos de BARON, Hans. Machiavelli: The Republican Citizen and the Autor of the Prince. In The English Historical Review, vol.76. London: Pharthes, 1971, pg.217/253; GILBERT, Felix. The humanist concept of the Prince of Machiavelli. Cambridge: Mass, 1977; GRAMSCI, Antonio. Maquiavel, a Política e o Estado Moderno. Rio de Janeiro: Civilização Brasileira, 1978.

${ }^{27}$ CHEVALIER, Jean-Jacques. História do Pensamento Político. Rio de Janeiro: Zahar Editores, 1990, pg. 265. Ver também SKINNER, Quentin. As fundações do pensamento político moderno. São Paulo: Companhia das Letras, 1996.

${ }^{28}$ A lei intervém para reprimir e combater esta má natureza dos homens, obrigando-os a conciliar o interesse individual como coletivo. PEREIRA, Joacil de Brito. Idealismo e realismo na obra de Maquiavel. Brasília: Horizonte, 1981, pg. 95. É curiosa a posição de Maquiavel no Discursi, em seu capítulo XVII, quando insiste com a tese de que um povo que tem êxito em suas conquistas acaba por relaxar e permitir-se degradar, partindo da premissa de que a corrupção se refere primordialmente aos costumes do povo que, uma vez corrompido, faz com que as instituições não produzam mais ações positivas ao bem comum. In MACHIAVELLI, Niccollò. Discursi sul a Prima Década di Tito Lívio. Op.cit., p.177 e 178.
} 
popolo minuto - os pobres e assalariados, e para consolidar uma proposta de unificação nacional de um país esfacelado ${ }^{29}$.

Não são muito diferentes as conclusões de outro autor importante no tema à Idade Moderna, Thomas Hobbes, ao dizer, no Sobre o Cidadão, que: "Por causa de nossa natureza, não buscamos a sociedade por si mesma; o que queremos é receber dela honras e vantagens; estas em primeiro lugar, aquelas, depois.”30

O ponto de partida da ação humana, moral e política, para Hobbes, é o esforço ou empenho (movimento), considerando o autor a vida como sendo uma corrida na qual é preciso vencer sempre, começa com um esforço inicial, que é a sensação do desejo; estar continuamente ultrapassado corresponderia à miséria, e ultrapassar quem está adiante corresponderia à felicidade. "Para todo o homem, outro homem é um concorrente, como ele, ávido de poder sob todas as suas formas. ..... Concorrência, desconfiança recíproca, avidez de glória ou de fama têm por resultado a guerra perpétua de cada um contra cada um, de todos contra todos.”31

A natureza humana, tão perniciosa ao próprio homem, é pintada por Hobbes com muito detalhismo, lembrando o autor que, entre os homens, se for para realizar tarefa comum, nasce certa amizade formal que tem em si mais de ciúme do que de amor; se alguém relatar um fato notável, os outros relatam também os milagres que fizeram, ou, se não fizeram, os inventam. "Toda sociedade, portanto, é forjada pela força do útil ou pelo estímulo da honra, isto é, por amor a si e não aos sócios e componentes.” 32

Mister é que se ateste com Bobbio ${ }^{33}$ que, enquanto no Sobre o Cidadão o pensador apresenta algumas condições objetivas de indissociabilidade do estado natural ${ }^{34}$, no Leviatã, Hobbes sustenta a existência de três causas principais de luta entre os homens, aprofundando melhor as conclusões empíricas de seu discurso, a saber: a competição que os homens travam

\footnotetext{
${ }^{29}$ Mais uma vez, aqui, sua veia humanitária se revela com força, haja vista sua indignação para com o tratamento desigual e marginalizante destinados aos menos favorecidos. Ver o excelente trabalho de CONDE, Francisco Javier. El Saber Político en Maquiavel. Madrid: Paidós, 1996, p.158.

${ }^{30}$ HOBBES, Thomas. De Cive. Elementos filosóficos a respeito do cidadão. Rio de Janeiro: Vozes, 1993, p.50.

${ }^{31}$ CHEVALLIER. Jean-Jacques. As Grandes Obras Políticas de Maquiavel a Nossos Dias. Rio de Janeiro: Agir, 1982, p.69.

${ }^{32}$ HOBBES, Thomas. De Cive. Op.cit., pp.52 e 53.

${ }^{33}$ BOBBIO, Norberto. Thomas Hobbes. Rio de Janeiro: Campus, 1991, p.35.

${ }^{34}$ Igualdade de fato; escassez dos bens; o direito de cada um sobre todas as coisas (o que gera a guerra). Neste ponto esclarece SABINE, George. Historia de la Teoria Politica. México: Fondo de Cultura Económica, 2007, p.343: "De esta exposición de los motivos humanos se sigue como cosa natural la descripción del estado del hombre fuera de la sociedad. Todo ser humano está movido únicamente por consideraciones que afectan a su propia seguridad o poder y los demás seres humanos le importan sólo en la medida en que afectan a esas consideraciones. Igualmente no hay justicia ni injusticia, derecho ni ilegalidad, ya que la norma de la vida consiste en que sólo pertenece a cada uno lo que puede tomar y sólo en tanto que puede conservalo.”
} 
entre si pelo ganho; a desconfiança que os faz lutar pela segurança; a glória que os faz combater pela reputação.

Por outro lado, “o governo republicano só é possível em cidades não corrompidas, estáveis e afortunadas. Ai, a liberdade deve ser confiada ao povo, pois nele é possível perceber uma vontade firme de viver em liberdade.” ${ }^{35}$ Tal vontade firme decorre daquela compreensão de virtudes cívicas referidas anteriormente. Mas e quando elas faltarem ao homem comum do povo? E quando os cidadãos da República não forem tão virtuosos assim? Está-se diante do mesmo problema antes cotejado, ou seja, será preciso na ausência da virtude algo que assegure os seus fundamentos e condutas consectárias a ela. E que algo é este?

No capítulo II, do Sobre o Cidadão, Thomas Hobbes assevera que uma das leis naturais derivadas da lei fundamental é que o direito de todos os homens a todas as coisas não deve ser mantido, mas é preciso transferir ou desistir de certos direitos, isto porque, se fosse ao contrário, implicaria que uns teriam o direito de ataque e outros o de defesa, ou, de forma extensiva, a guerra. ${ }^{36}$

É um dever racional do homem natural que pretende se emancipar de tal condição perceber e tomar consciência da necessidade de se portar de acordo com os fins a que quer chegar: felicidade, segurança e prosperidade, o que significa dizer, desistir do direito de livre postura e agir, transferindo-o a outrem.

Estas condutas voltadas para a paz devem ser observadas por todos os homens, ou pela maioria, o que não ocorre no Estado de Natureza, eis que inexiste ali alguém bastante forte para obrigá-los a observá-las. Assim, o único caminho para tornar eficazes as leis naturais, ou seja, para fazer com que os homens atuem segundo a razão e não segundo a paixão, é a instituição de um poder tão irresistível que torne desvantajosa a ação contrária: o Estado e seus aparatos institucionais e jurídicos.

Não que as promessas da República democrática tenham ruído completamente, mas precisaram ser ancoradas em mecanismos menos ideais e mais pragmáticos de controle e garantias, corregedores de desvios comportamentais corruptivos, permanentemente aprimorados. Em outras palavras, "la condición primera de la sociedad es la mutua confianza y el cumplimiento de los pactos ya que sin ella no puede haber certeza de su efectividad, pero

\footnotetext{
${ }^{35}$ MACHIAVELLI, Niccollò. Discursi sul a Prima Década di Tito Lívio. Op.cit., Capítulo V. Ver também o excelente texto de BIGNOTTO, Newton. Maquiavel republicano. São Paulo: Loyola, 1991.

${ }^{36}$ HOBBES, Thomas. De Cive. Op.cit., p.62. Ver meu texto LEAL, Rogério Gesta. Teoria do Estado: cidadania e poder político na modernidade. Porto Alegre: Livraria do Advogado, 2001.
} 
tiene que haber una presunción razonable de que las demás personas se colocarán en la misma posición.”37

Na construção teórica de Hobbes, o Estado, entre outras coisas e autorizado pelo pacto social, detém o monopólio do aparato legal, e, uma vez constituído, não existe outro referencial de regulação e ordenamento social que não as leis civis, as quais, de forma inarredável, servem como critério do justo e do injusto para os súditos, e, observe-se, são características do poder supremo exercido pelo Estado, fazer e ab-rogar leis, donde a conclusão inevitável: o Estado é a fonte do direito, ele não reconhece direitos preexistentes, mas os cria ao promulgá-los. ${ }^{38}$

O problema aqui é que também não se pode reduzir a corrupção à mera violação da legalidade, mitigando o seu aspecto de imoralidade pública e privada decorrente de vícios éticos recorrentes em vários âmbitos da vida quotidiana, sob pena de autorizar argumentos que defendam tratá-la como qualquer outro ilícito ou delito - inclusive para os efeitos de caracterizar situações corruptivas como de menor potencial ofensivo à sociedade e às suas vítimas (crime de bagatela, por exemplo), decorrendo daí impunibilidades.

Esta construção discursiva, todavia, revela a ausência de medidas que procurem dar eficácia às finalidades do Estado, eis que inexistem sanções ao soberano pelo descumprimento das tarefas que lhe são impostas, ao menos no plano material do cotidiano dos cidadãos, e isto se explica, primeiro, pela impossibilidade de existir sanção contra alguém que é incensurável, e segundo, em razão da soberania do próprio Estado, seus atos gozam da presunção da legitimidade pactuada, inatingível, por pura lógica, pela negação de seu mister.

Se de um lado o pensador tenta aplacar o poder conferido pelo contrato entre os súditos com a disposição de uma finalidade a ser alcançada pelo governo do soberano, que é garantir a felicidade e o desenvolvimento ordenado da sociedade, por outro, não traz nenhuma forma de contestação ou solução aos desvios de caminhos levados a cabo pelo Poder instituído, exatamente porque o seu poder é perpétuo e absoluto. ${ }^{39}$ Este será um tema muito pragmático à filosofia política dos primeiros tempos da modernidade.

Na mesma linha vai Montesquieu, ao sustentar que a corrupção de cada governo começa quase sempre pela corrupção dos princípios ${ }^{40}$, e, neste caso, “somente as leis podem corrigir a imoralidade do interesse por meio da coerção, tornando a ação humana reta no

\footnotetext{
${ }^{37}$ SABINE, George. Historia de la Teoria Política. Op.cit., p.347.

${ }^{38}$ Ver HOBBES, Thomas. Leviathã. In Os Pensadores. São Paulo: Nova Cultural.1988.

${ }^{39}$ Sobre o ponto, vale a pena a leitura de MANENT, Pierre. Naissance de la politique moderne: Machiavel, Hobbes, Rousseau. Paris: Payot, 2006.

${ }^{40}$ MONTESQUIEU. O Espírito das Leis. Brasília: UnB, 2001, p.124.
} 
sentido de uma ética derivada da realidade efetiva das coisas, que opera no plano externo da consciência. A moral se separou da política, na modernidade, demandando ao Direito o papel de enunciação dos valores.”41

Diz o autor francês que um Estado pode mudar de duas maneiras: ou porque a Constituição se corrige, ou porque ela se corrompe. Se ele conservou seus princípios e a Constituição muda, é que ela se corrige; se ele perdeu seus princípios, quando a Constituição vem a mudar é que ela se corrompe. ${ }^{42}$ Em suas próprias palavras:

\begin{abstract}
"Quando essa virtude finda, a ambição entra nos corações que podem recebê-la, e a avareza entra em todos. Os desejos mudam de objetos: o que se amava, não se ama mais; era-se livre com as leis, se quer ser livre contra elas; cada cidadão é como um escravo que escapou da casa de seu senhor; o que era máxima chama-se rigor; o que era regra chama-se embaraço; o que aí era respeito chama-se medo. A frugalidade é agora a avareza, e não o desejo de possuir. Outrora os bens dos particulares constituíam o tesouro público, mas desde então, o tesouro público torna-se o patrimônio dos particulares. A república é um despojo, e sua força não é mais do que o poder de alguns cidadãos e a licença de todos." ${ }^{33}$
\end{abstract}

Bignotto acentua esta percepção de Montesquieu esclarecendo que o autor definia a República pelo princípio da Virtude, sendo que a perda desta por parte da cidadania evidenciava sinal explícito de degradação corruptiva de todo o regime político. Ou seja, “a virtude orienta as ações dos habitantes de uma república e que, quando ela desaparece ou deixa de guiar as ações políticas, todo um conjunto de valores desaparece ou deixa de ser fundamental. Por isso, o regime se corrompe, ou perde sua identidade, expressa no mais das vezes, em suas leis fundamentais.”44

Já para Rousseau, a degeneração da política e do Estado/governo se apresentava como algo inexorável, haja vista que a relação que este mantém com o povo soberano vem sempre marcado por níveis de conflituosidade significativos, impossíveis de serem exterminados, apenas gestados:

\footnotetext{
${ }^{41}$ FILGUEIRAS, Fernando. Corrupção, Democracia e Legitimidade. Op.cit., p.71. Lembra o autor que: "Dessa forma, a república democrática é corrompida quando as virtudes cívicas dão lugar aos interesses privados - o cidadão não mais quer obedecer à autoridade legítima do Estado, mas às próprias convicções -, resultando na desordem, tal como ocorreu em Roma.” (p.74).

${ }^{42}$ MONTESQUIEU. O Espírito das Leis. Op.Cit., p.141.

${ }^{43}$ Idem, p.145.

${ }^{44}$ BIGNOTTO, Newton. Republicanismo. In AVRITZER, Leonardo (org.). Corrupção: ensaios e críticas. Belo Horizonte: UFMG, 2008, p.106. Lembra o autor a obra de PETTIT, Philip. Republicanism. Oxford: Oxford University Press, 1999, partindo da idéia de que as pessoas que se ocupam do poder não são todas corruptas, mas são todas corruptíveis; se todas fossem corruptas, as instituições republicanas seriam incapazes de lidar com a virtude dos cidadãos, razão pela qual a preocupação maior tem de ser a preservação do caráter virtuoso de alguns e o combate dos vícios corruptivos de outros.
} 
“O corpo político, assim como o corpo do homem, começa a morrer desde seu nascimento e carrega em si mesmo as causas de sua destruição. Mas um e outro podem ter uma constituição mais ou menos robusta e própria a conservá-los mais ou menos tempo. A constituição do homem é obra da natureza, a do Estado é obra da arte. Não depende dos homens prolongarem sua vida, depende deles prolongar a do Estado tão longe quanto é possível, dando-lhe a melhor constituição que ele possa ter. O mais bem constituído acabará, mas mais tarde do que o outro, se nenhum acidente imprevisto levar à sua perda antes do tempo.”45

Em face deste diagnóstico insiste Rousseau que em cada Estado deve haver um equilíbrio entre o poder do soberano e do governo, a fim de que este cumpra sua função sem desviar-se ou abusar de suas atribuições. Mesmo assim, é impossível manter tal equilíbrio por todo o tempo, sendo inexorável que ela se desfaça, pois “deve acontecer cedo ou tarde que o príncipe oprima enfim o soberano e rompa o tratado social. Está aí o vício inerente e inevitável que, desde o nascimento do corpo político, tende sem descanso a destruí-lo, assim como a velhice e a morte destroem o corpo do homem." ${ }^{46}$

Já no Discurso sobre a economia política Rousseau advertia para o fato de que dos conflitos entre interesses particulares e públicos, em regra, os vícios públicos sobrepujam-se, inclusive sobre as leis, às quais os cidadãos estariam obedecendo apenas aparentemente para, depois, poder infringi-las com mais segurança. Assim, “o povo, que não vê que seus vícios são a primeira causa de seus infortúnios, murmura e chora gemendo: Todos os meus males vêem apenas daqueles que eu pago para me proteger deles.”47

A alienação do povo em relação aos temas de interesse público e em face do Estado é referida por Rousseau como sintomas terminais da enfermidade do corpo político, ou seja, se os cidadãos preferem servir ao Estado com seu dinheiro sem se dedicarem pessoalmente às atividades públicas, isto significa que a ruína já está a caminho, tendo presente que tal fenômeno se dá somente em meio às relações sociais - diferente, pois, das teses religiosas de

\footnotetext{
${ }^{45}$ ROUSSEAU, Jean Jacques. Discurso sobre a origem e os fundamentos das desigualdades entre os homens $e$ O Contrato Social. Capítulo 3, livro XI. São Paulo: Abril Cultural, 1978, p.23.

46 ROUSSEAU, Jean Jacques. O Contrato Social. Op.cit., Capítulo 3, livro XI. Para evitar o máximo esta anunciada usurpação do poder pelo príncipe, Rousseau insiste para que o povo soberano se reúna cada vez mais em assembléias para exercitar o controle do exercício do poder político. Esta, aliás, é também uma preocupação de Montesquieu - a despeito de que dirigida à necessidade não do povo se reunir periodicamente, mas dos seus representantes, para evitar o poder absoluto e incontrolável do governo: "Se o corpo legislativo estivesse um tempo considerável sem ser reunido, não haveria mais liberdade. Pois aconteceria uma destas duas coisas: ou não haveria mais resolução legislativa e o Estado cairia na anarquia; ou essas resoluções seriam tomadas pelo poder executivo e ele se tornaria absoluto.” MONTESQUIEU. O Espírito das Leis. Op.Cit., p,151.

47 ROUSSEAU, Jean Jacques. Discurso sobre a economia política. Brasília: UNB, 1985, p.27. Na mesma direção ver o texto ROUSSEAU, Jean Jacques. Discurso sobre a origem e os fundamentos da desigualdade entre os homens. Brasília: UNB, 1989.
} 
que o homem é um ser decaído por natureza, carregando em sua existência terrena máculas de origem que explicam suas fraquezas e perversões, o que o levaria à corrupção. ${ }^{48}$

De certa forma a própria democracia representativa vai se ressentir desta previsão rousseauniana - aliás, não só dele, considerando que Tocqueville da mesma forma o fez quando tratou da liberdade política nesta matriz democrática, exigindo a ação cívica da cidadania em face dos representantes, no intento de infundir neles o compromisso de persecução do bem comum, e monitorar/cobrar suas ações, sob pena destes alçarem tal nível de autonomia e independência dos seus representados (fonte legítima do poder) a ponto de se transformarem numa espécie de nova casta. ${ }^{49}$

O liberalismo político, econômico e moral, todavia, não ajudou muito neste debate, exatamente pelo fato de sustentar que uma comunidade justa é aquela que propicia a seus membros as condições para que cada um possa agir com base em suas próprias convicções, não cabendo à autoridade política determinar os objetivos e fins - por mais nobres que sejam - aos quais as pessoas devem se empenhar para alcançar, uma vez que inexiste doutrina ou fórmula verdadeira - religiosa, política ou moral - sobre o que constitui a boa vida para o homem. ${ }^{50}$

Desde John Locke, Benjamin Constant e mesmo John Stuart Mill, vem se constituindo a tese de que:

\begin{abstract}
"Um Estado liberal justo deveria limitar sua intervenção à garantia de uma estrutura de instituições políticas, legais (o Estado de Direito) e socioeconômicas sob a qual indivíduos e grupos podem perseguir os fins e objetivos que julgarem corretos sujeitando-se a algo similar ao "Harm Priciple" de John Stuart Mill, segundo o qual a coerção coletiva da sociedade só pode ser empregada para restringir a liberdade individual quando isto for necessário para evitar que danos sejam causados a outros." 51
\end{abstract}

Ora, mas de que danos se fala e com base em que princípos e valores violados? Está se tratanto tão somente de danos individuais e materiais (de propriedade, liberdade, etc.)?

\footnotetext{
${ }^{48}$ ROUSSEAU, Jean Jacques. Discurso sobre a origem $e$ os fundamentos das desigualdades entre os homens $e$ O Contrato Social. Op.cit., p.35. Ver o texto de ARAÚJO, Cícero. Rousseau e Hume. In AVRITZER, Leonardo (org.). Corrupção: ensaios e críticas. Op.citada.

${ }^{49}$ Ver o texto de TOCQUEVILLE, Alex. O Antigo Regime e a Revolução. Brasília: UNB, 1998. Da mesma forma TOCQUEVILLE, Alex. A Democracia na América. São Paulo: Martins Fontes, 2005. A liberdade política estaria corrompida pela ausência de uma cidadania ativa responsável pela gestão da coisa pública.

${ }^{50}$ Ver o excelente texto de VITA, Álvaro de. Liberalismo. In AVRITZER, Leonardo (org.). Corrupção: ensaios e críticas. Op.cit., p.93.

${ }^{51}$ Idem, p.94. Sem contar, como adverte o autor, com as facções fundamentalistas como a do libertarianismo, associada a autores como Friedrich Hayek, James Buchanan e Robert Nozick, defensores da liberdade negativa, sustentando a não interferência da autoridade política e de quem quer que seja, nos direitos de propriedades ou titularidades adquiridos por meio de transações voluntárias não fraudulentas.
} 
Provavelmente sim! Isto porque o conceito de Direitos Fundamentais Sociais aqui não é objeto de preocupação distinguida, faltando à tradição liberal - ao menos em sede de fundamentos clássicos - a noção de interesse público, difuso e coletivos, necessários à discussão do tema da corrupção.

Aliás, as teses que ancoram a explicação das bases constitutivas da corrupção na degradação das virtudes individuais e nas práticas vilipendiadoreas do interesse público (que importância alguma tem nestes cenários), de igual sorte sobrecarregam a responsabilidade deste complexo fenômeno nas ações comportamentais de pessoas, pouco valorando a contribuição dada pela inércia e cumplicidade das instituições democráticas.

\section{CONCLUSÃO}

A reflexão que desenvolvi até aqui também serve - como disse acima - para entender melhor como os Direitos Humanos e Fundamentais são letalmente impactados pelos atos corruptivos, na medida em que, por exemplo, "the ability to promote and protect civil and political rights rests upon effectively combating political and judicial corruption (and vice versa). Transparency and access to information empower individuals to make informed decisions - from exercising their voting rights, to monitoring how state expenditures are spent." 52

Quando a corrupção encontra-se dispersa em todo o corpo político e mesmo tolerada pela comunidade, as pessoas mais necessitadas sofrem de forma mais direta com os efeitos disto, haja vista que as estruturas dos poderes instituídos se ocupam, por vezes, com os temas que lhes rendem vantagens seja de grupos, seja de indivíduos, do que com os interesses públicos vitais existentes: hospitais públicos deixam de atender pacientes na forma devida porque são desviados recursos da saúde para outras rubricas orçamentárias mais fáceis de serem manipuladas e desviadas como prática de suborno e defraudação; famílias em situação de pobreza e hipofuciencia material não podem se alimentar porque os recursos de programas sociais são desviados para setores corruptos do Estado e da Sociedade Civil; as escolas públicas não têm recursos orçamentários à aquisição de material escolar em face dos desvios

\footnotetext{
${ }^{52}$ ANECHIARICO, Frank \& JACOBS, James B. The Pursuit of Absolute Integrity: How Corruption Control Makes Government Ineffective. Chicago: University of Chicago Press, 1998, p.71. E acrescenta o autor: "At the same time, creating such openness limits opportunities for abuses by politicians, police and judges. When accountability mechanisms are weak or non-existent, it becomes too easy for violations to occur.”
} 
de recursos para outros fins, e os alunos ficam sem condições de formação minimamente adequadas.

Heloisa Starling, em instigante texto, lembra que:

\begin{abstract}
"Na sua origem grega, a palavra corrupção aponta para dois movimentos: algo que se quebra em um vínculo; algo se degrada no momento dessa ruptura. As consequencias são consideráveis. De um lado, quebra-se o princípio da confiança, o elo que permite ao cidadão associar-se para interferir na vida de seu país. De outro, degrada-se o sentido do público. Por conta disso, nas ditaduras, a corrupção tem funcionalidade: serve para garantir a dissipação da vida pública. Nas democracias e diante da República - seu efeito é outro: serve para dissolver os princípios políticos que sustentam as condições para o exercício da virtude do cidadão."53
\end{abstract}

É claro que, por outro lado, a corrupção também pode atingir estes Direitos Fundamentais pela via dos comportamentos corruptivos de alguns cidadãos - evidenciando, por certo, a falha estatal de evitar isto -, como quando alguém paga suborno para obter determinado tratamento médico-hospitalar; ou paga suborno para conseguir vaga escolar, condutas estas que estão a violar o sistema de ensino e de saúde existente. E até indiretamente, como quando autoridades estatais permitem, pela via do suborno, que sejam comercializados resíduos tóxicos e depositados sem as cautelas devidas em áreas de densidade demográfica significativa, gerando às pessoas destas localidades danos as suas saúdes ao longo do tempo.

Veja-se que, aqui, há igualmente explicita violação do direito de igualdade que as Constituições contemporâneas garantem modo geral, pois se dá tratamento diferenciado a pessoas em face de serviços e atividades que deveriam atender de forma isonômica a todos. ${ }^{54}$

Como diz Lambsdorff, tais demandas envolvem Direitos Fundamentais Civis, Políticos, Sociais, Econômicos e Culturais, sem distinção, implicando altos custos de investimento e proteção, profundamente atingidos por atos corruptivos que esvaziam os recursos públicos:

"The obligation to fulfill requires the state to take measures to ensure that people under its jurisdiction can satisfy basic needs (as recognized in human rights instruments) that they cannot secure by their own efforts. Although this is the key

\footnotetext{
53 STARLING, Heloisa Maria Murgel. Ditadura Militar. In AVRITZER, Leonardo (org.). Corrupção: ensaios e críticas. Belo Horizonte: UFMG, 2008, p.259.

54 Como diz PRESTON, Noel, and SAMPFORD, Charles (eds.). Encouraging Ethics and Challenging Corruption. Sydney: Federation Press, 2002, p.54: "When a person obtains privileged treatment by means of a bribe (when applying for an official document such as a passport or visa, for example, or clearing goods from customs without paying duties and taxes), no other human right is necessarily directly affected except the right to equality, i.e. the right to be treated equally when obtaining the visa or when clearing goods from customs.”
} 
state obligation in relation to economic, social and cultural rights, the duty to fulfill also arises in respect to civil and political rights. It is clear, for instance, that enforcing the prohibition of torture (which requires states to investigate and prosecute perpetrators, pass laws to punish them and take preventive measures such as police training), or providing the rights to a fair trial (which requires investment in courts and judges), to free and fair elections, and to legal assistance, all require considerable costs and investments." 55

Nesta perspectiva, há que se perguntar quais as melhores estratégias de lidar com este tema? Assunto para outras indagações futuras.

\section{REFERÊNCIAS}

ABED, George T. \& GUPTA, Sanjeev (eds.). Governance, Corruption, and Economic Performance. Washington DC: International Monetary Fund, 2003.

ANECHIARICO, Frank \& JACOBS, James B. The Pursuit of Absolute Integrity: How Corruption Control Makes Government Ineffective. Chicago: University of Chicago Press, 1998.

ARISTÓTELES. Ética a Nicômaco. In Aristóteles (II), coleção Os Pensadores. São Paulo: Abril Cultural, 1984.

BAKER, Raymond. Capitalism's Achilles Heel: Dirty Money and How to Renew the Free-Market System. Indianapolis: Wiley, 2005.

BARON, Hans. Machiavelli: The Republican Citizen and the Autor of the Prince. In The English Historical Review, vol.76. London: Pharthes, 1971.

BIGNOTTO, Newton. Maquiavel republicano. São Paulo: Loyola, 1991.

Republicanismo. In AVRITZER, Leonardo (org.). Corrupção: ensaios e críticas. Belo Horizonte: UFMG, 2008.

BOBBIO, Norberto. Thomas Hobbes. Rio de Janeiro: Campus, 1991.

CHEVAliER, Jean-Jacques. História do Pensamento Político. Rio de Janeiro: Zahar Editores, 1990. 1982.

As Grandes Obras Políticas de Maquiavel a Nossos Dias. Rio de Janeiro: Agir,

CÍCERO, Marco Túlio. Dos Deveres. São Paulo: Martin Claret, 2001.

\footnotetext{
${ }^{55}$ LAMBSDORFF, Johann Graf. The Institutional Economics of Corruption and Reform: Theory, Evidence and Reform. Cambridge: Cambridge University Press, 2007, p.88.
} 
CONDE, Francisco Javier. El Saber Político en Maquiavel. Madrid: Paidós, 1996.

CRANK, John \& CALDERO, Michael. Police Ethics: The Corruption of Noble Cause. Cincinnati: Anderson Publishing, 2004.

FILGUEIRAS, Fernando. Corrupção, Democracia e Legitimidade. Belo Horizonte: UFMG, 2008.

GIBBON, Edward. Declínio e queda do Império Romano. São Paulo: Companhia das Letras, 1989.

GILBERT, Felix. The humanist concept of the Prince of Machiavelli. Cambridge: Mass, 1977.

GRAMSCI, Antonio. Maquiavel, a Política e o Estado Moderno. Rio de Janeiro: Civilização Brasileira, 1978.

HALE, Jonh. Maquiavel e a Itália da Renascença. Rio de Janeiro: Zahar Editores, 1970.

HOBBES, Thomas. De Cive. Elementos filosóficos a respeito do cidadão. Rio de Janeiro: Vozes, 1993.

Leviathã. In Os Pensadores. São Paulo: Nova Cultural,1988.

KLITGAARD, Robert. Controlling Corruption. Berkeley: University of California Press, 1991.

LAMBSDORFF, Johann Graf. The Institutional Economics of Corruption and Reform: Theory, Evidence and Reform. Cambridge: Cambridge University Press, 2007.

LEAL, Rogério Gesta. Teoria do Estado: cidadania e poder político na modernidade. Porto Alegre: Livraria do Advogado, 2001.

MACHIAVELLI, Niccollò. Discursi sul a Prima Década di Tito Lívio. Nápoles: Daltricce, 1978.

MANENT, Pierre. Naissance de la politique moderne: Machiavel, Hobbes, Rousseau. Paris: Payot, 2006.

MILLER, Seumas \& BLACKLER, John. Ethical Issues in Policing. Aldershot: Ashgate, 2005.

MILLER, Seumas, ROBERTS, Peter \& SPENCE, Edward. Corruption and AntiCorruption: An Applied Philosophical Approach. New Jersey: Prentice Hall, 2008.

MILLER, Seumas. The Moral Foundations of Social Institutions: A Philosophical Study. New York: Cambridge University Press, 2010.

MONTESQUIEU. O Espírito das Leis. Brasília: UnB, 2001, p.124. 
MOODY-STUART, George. Grand Corruption: How Business Bribes Damage Developing Countries. Oxford: World View Publishing, 1997.

PEREIRA, Joacil de Brito. Idealismo e realismo na obra de Maquiavel. Brasília: Horizonte, 1981.

PETTIT, Philip. Republicanism. Oxford: Oxford University Press, 1999.

PLATÃO. A República. Belém: Edufpa, 2000. PLATÃO.

As Leis. Belém: Edufpa, 1980.

PRESTON, Noel, and SAMPFORD, Charles (eds.). Encouraging Ethics and Challenging Corruption. Sydney: Federation Press, 2002.

RIDOLFI, Ricardo. Vita di Niccolò Machiavelli. Roma: Domenico, 1974.

ROUSSEAU, Jean Jacques. Discurso sobre a economia política. Brasília: UNB, 1985.

Discurso sobre a origem e os fundamentos das desigualdades entre os homens e O Contrato Social. Capítulo 3, livro XI. São Paulo: Abril Cultural, 1978.

SABINE, George. Historia de la Teoria Politica. México: Fondo de Cultura Económica, 2007.

SKINNER, Quentin. As fundações do pensamento político moderno. São Paulo: Companhia das Letras, 1996.

STARLING, Heloisa Maria Murgel. Ditadura Militar. In AVRITZER, Leonardo (org.). Corrupção: ensaios e críticas. Belo Horizonte: UFMG, 2008.

TERRIEL, Jean. Les theories du pacte social. Droit naturel, souveranite et contract de Bodin a Rousseau. Paris: PUF, 2001.

TOCQUEVILLE, Alexis de. O Antigo Regime e a Revolução. Brasília: UNB, 1998.

A Democracia na América. São Paulo: Martins Fontes, 2005.

TUGENDHAT, Ernst. Lições sobre Ética. Petrópolis: Vozes, 1999.

UNITED NATIONS COMMISSION ON HUMAN RIGHTS, Interim Report of the Special Representative of the Secretary-General on the Issue of Human Rights and Transnational Corporations and Other Business Enterprises, U.N. Doc. E/CN.4/2006/97, 22 February 2006. 